\title{
A PMSG/GnRH method for the superovulation of the monovulatory brush-tailed possum (Trichosurus vulpecula)
}

\author{
J. C. Rodger and K. E. Mate \\ Department of Biological Sciences, University of Newcastle, New South Wales 2308, Australia
}

\begin{abstract}
Summary. Optimal ovarian stimulation with minimal degenerative changes was achieved in brush-tailed possums 3 days after a subcutaneous injection of 10 i.u. PMSG. This treatment alone did not result in ovulation and only rarely in oocyte maturation. Ovulation of 8-24 mature oocytes occurred when on the 3rd day after 10 i.u. PMSG the female received 3 intramuscular injections of $50 \mu \mathrm{g}$ synthetic gonadotrophin-releasing hormone (GnRH) $90 \mathrm{~min}$ apart. Superovulation was achieved in immature, cycling, pregnant and lactating females, but not in animals in the preovulatory phase of a natural oestrous cycle.
\end{abstract}

Keywords: superovulation; marsupial; brush-tailed possum; PMSG; GnRH

\section{Introduction}

Simple reliable methods to manipulate marsupial breeding and productivity would aid research and are essential if the early development of marsupials is to be studied experimentally at a cellular and molecular level. They would also have considerable application in the husbandry of captive animals and in efforts to conserve endangered species. Finally, such techniques would encourage more efficient use of wild animals in research and assist in the development of true laboratory species.

Artificial breeding is a multifaceted problem but arguably the most critical factor is the induction of ovulation and oestrus. Removal of sucking pouch young reactivates the ovary and induces ovulation and oestrus 8 days later in the brush-tailed possum (Pilton \& Sharman, 1962). This technique has been a mainstay of marsupial reproductive biology (see Tyndale-Biscoe \& Renfree, 1987) but it requires sacrificing young (an undesirable and often unacceptable or impractical procedure) and the timing of the induced oestrus and ovulation is imprecise (Rodger \& Bedford, 1982). Furthermore, many of the Australian species of interest (e.g. tammar wallaby, Macropus eugenii) are monovulatory and with current manipulations can at most produce only a few eggs or embryos per year (Tyndale-Biscoe \& Hinds, 1984; Rodger et al., 1985).

There have been several attempts to induce ovulation or superovulation of marsupials by treatment with exogenous gonadotrophins but a practical system has not been established. Two polyovulatory species have been studied: the American opossum, Didelphis virginiana (Nelson \& Maxwell, 1941; Nelson \& White, 1941) and the Australian dasyurid Sminthopsis crassicaudata (Smith \& Godfrey, 1970). In both cases induction of ovulation was claimed using PMSG and/or human chorionic gonadotrophin (hCG) but no offspring were produced. Superovulation has been attempted in one monovulatory species, the Australian brush-tailed possum, Trichosurus vulpecula (Harding, 1969). Significant ovarian stimulation was achieved in this study using multiple injections of PMSG alone or in combination with hCG. However, oocytes were often trapped in luteinizing follicles and superovulated oocytes were found in only 3 animals.

The present study re-examined the brush-tailed possum's response to PMSG. PMSG, the equine chorionic gonadotrophin, remains the agent of choice for superovulation of many eutherian 
laboratory and domestic animals, despite its tendency to overstimulate, because its long half-life means single treatments are effective and it is inexpensive.

\section{Materials and Methods}

Brush-tailed possums (Trichosurus vulpecula) were live trapped in the Newcastle region and housed in individual cages at the University of Newcastle Central Animal House. They had access to water ad libitum and were fed a diet of fresh fruit, vegetables and dry dog food. This artificial diet was supplemented with native foliage and blossom as available. Most animals were used within 2 weeks of capture. Three additional animals (Nos 41, 45 \& 46) were caught in the Adelaide suburbs and housed, treated and examined at the Department of Genetics, University of Adelaide.

PMSG (Folligon: Intervet, Oss, The Netherlands) was administered as a subcutaneous injection in sterile water at the doses indicated in Tables 1 and 2. Synthetic GnRH (Fertagyl: Intervet) was used as supplied for intramuscular injection at the doses indicated in Table 2. Possums were killed by an intraperitoneal overdose of barbiturate (Lethabarb: Arnolds, Reading, U.K.) and the reproductive tract removed. The times at which animals were killed and examined is indicated in the Tables. These times were chosen to allow a variety of periods of exposure to PMSG and to gain information on the timing of ovulation after $\mathrm{GnRH}$. The ovaries were first examined for signs of stimulation or ovulation and the diameters of follicles projecting from the surface were measured with vernier calipers to the nearest $0.1 \mathrm{~mm}$. When ovulation had not occurred, follicular oocytes were recovered from several of the largest follicles in the left ovary and then mounted and examined fresh and after fixation and staining to identify their maturation status (Bedford, 1971).

When ovulation had occurred the eggs were recovered from the tract by flushing the oviduct via its uterine end or the whole tract via the cervix, using a needle and syringe. Heparin $(12.5 \mathrm{i} . u . / \mathrm{ml})$ was included in the flushing medium (Hank's Balanced Salt Solution; Flow Laboratories, Irvine, U.K.) as an anticoagulant. In highly vascular tracts cutting the upper uterus to flush the oviduct caused marked bleeding and some eggs were lost in the coagulum. Subsequently, ovulated oocytes were routinely recovered by flushing the uterus and oviduct as one piece. This meant that definitive identification of their location was not possible. Ovulated oocytes were mounted and examined for their maturation state in the same way as follicular oocytes.

The right ovary was routinely fixed in Bouin's solution and processed for light microscopy by routine wax histology and haematoxylin and eosin stained slides were prepared. Slides were examined to confirm the state of oocyte maturation and the histological normality of the ovary.

\section{Results}

Recruitment of many (range 8-17/ovary) medium to large Graafian follicles was achieved at all single PMSG doses above $10 \mathrm{i} . \mathrm{u}$. in immature and mature cycling and lactating females (Table 1). Multiple 50 or 100 i.u. doses of PMSG also led to ovarian stimulation (range 12-20 medium to large follicles/ovary). However, animals in the preovulatory phase of a natural cycle or one induced by removal of a pouch young failed to respond (Nos 5, 6,9, 10\&11) or had a poor response (Nos 8 $\& 18$ ) (Table 1). Despite the marked ovarian response to PMSG, ovulation did not occur and in only 3 animals (Nos 3, 13 \& 19) had follicular oocytes resumed meiosis. Loss of granulosa cells from the surface of the zona pellucida was often observed but appeared to be a degenerative, rather than maturational, change. High single doses (200 and 1000 i.u.) of PMSG and multiple moderate doses ( 50 or $100 \mathrm{i.u./day}$ ) led to degenerative changes in follicular oocytes, particularly breakdown of the envelope of the germinal vesicle and loss of the nucleolus (Fig. 1). These oocyte changes were accompanied by luteinization of follicles and ovarian tissue and premature vascularization of follicles, trapping oocytes (Fig. 2).

On the basis of this experience attempts were made to induce superovulation by treatment with synthetic gonadotrophin-releasing hormone (GnRH). Evans et al. (1980) had shown, in line with eutherian studies, that GnRH induced an endogenous luteinizing hormone (LH) surge in the tammar wallaby. Initially single doses of GnRH (100 to $175 \mu \mathrm{g}$ ) were tested but failed to induce superovulation. However, three $50 \mu \mathrm{g}$ injections $90 \mathrm{~min}$ apart led to ovulation in 8 out of 15 animals (8-24 oocytes/animal) (Table 2). For 6 of the 7 animals which failed to ovulate; one (No. 25) appeared preovulatory in that very large follicles were present and the oocytes were at the metaphase II/first polar body stage; 2 (Nos 23 b \& 24) were treated with GnRH at 4 rather than 3 
Table 1. The ovarian response of brush-tailed possums to PMSG

\begin{tabular}{|c|c|c|c|c|c|c|}
\hline \multirow[b]{2}{*}{$\begin{array}{l}\text { PMSG dose } \\
\text { (i.u./day) }\end{array}$} & \multirow[b]{2}{*}{ Animal* } & \multicolumn{5}{|c|}{ Ovarian response } \\
\hline & & $\begin{array}{c}\text { Day } \\
\text { killed }\end{array}$ & $\mathrm{Y} / \mathrm{N}^{+}$ & $\begin{array}{c}\text { Maximum } \\
\text { follicular } \\
\text { diam. }(\mathrm{mm})^{\ddagger}\end{array}$ & $\begin{array}{l}\text { Oocyte } \\
\text { state§ }\end{array}$ & $\begin{array}{c}\text { Natural } \\
\text { ovulation }\end{array}$ \\
\hline \multicolumn{7}{|c|}{ Single (on Day 0) } \\
\hline 1 & 5 M RPY $4(21)$ & 10 & $\mathbf{N}$ & - & - & lov/egg \\
\hline 5 & 6 M RPY4(18) & 10 & $\mathbf{N}$ & - & - & lov/egg \\
\hline \multirow[t]{7}{*}{10} & $1 \mathrm{IM}$ & 4 & $Y(17)$ & $3 \cdot 1$ & GV/ZP & \multirow{7}{*}{$\begin{array}{l}\text { 1CL } \\
\text { lCL } \\
\text { lov/egg }\end{array}$} \\
\hline & $2 \mathrm{IM}$ & 4 & $Y(9)$ & $3 \cdot 7$ & GV/ZP & \\
\hline & $3 \mathrm{M}$ & 4 & $Y(8)$ & $3 \cdot 2$ & $\mathrm{PRO} / \mathrm{ZP}$ & \\
\hline & $4 \mathrm{M}$ & 4 & $\mathrm{Y}(14)$ & $3 \cdot 1$ & GV & \\
\hline & 8 M RPY0(5) & 10 & $\mathrm{Y} / \mathrm{N}(10)$ & $2 \cdot 6$ & GV & \\
\hline & 9 M RPY2(13) & 10 & $\mathrm{~N}$ & - & - & \\
\hline & $11 \mathrm{M}$ & 6 & $\mathbf{N}$ & - & - & \\
\hline 20 & $10 \mathrm{M}$ & 10 & $\mathbf{N}$ & - & - & \multirow[t]{4}{*}{$1 \mathrm{CL}$} \\
\hline 200 & 12 M PY(24) & 4 & $\mathrm{Y} / \mathrm{N}(13)$ & $2 \cdot 8$ & GV & \\
\hline \multirow[t]{2}{*}{1000} & 14 IM & 5 & $\mathrm{Y} / \mathrm{N}(8)$ & $2 \cdot 5$ & $\mathrm{DEG} / \mathrm{ZP}$ & \\
\hline & 15 M PY(76) & 5 & $\mathrm{~N}$ & - & $\mathrm{DEG} / \mathrm{GV}$ & \\
\hline \multicolumn{7}{|c|}{ Multiple (on Days 0-5) } \\
\hline \multirow[t]{3}{*}{50} & $19 \mathrm{IM}$ & 6 & $Y(15)$ & $3 \cdot 4$ & $\mathbf{M E T} / \mathbf{Z P}$ & \multirow{5}{*}{$1 \mathrm{CL}$} \\
\hline & 13 M PY(21) & 6 & $Y(20)$ & $4 \cdot 6$ & $\mathrm{MET} / \mathrm{PBI}$ & \\
\hline & $18 \mathrm{M}$ PY $(>60)$ & 6 & $\mathrm{Y} / \mathrm{N}(25)$ & $2 \cdot 6$ & $\mathrm{DEG} / \mathbf{Z P}$ & \\
\hline \multirow[t]{2}{*}{100} & $16 \mathrm{M} P Y(>60)$ & 6 & $Y(12)$ & $3 \cdot 2$ & $\mathrm{GV} / \mathrm{ZP}$ & \\
\hline & 17M PY $(68)$ & 6 & $Y(12)$ & 3.6 & GV/ZP & \\
\hline
\end{tabular}

*Immature (IM) females were juveniles which had never bred. Mature (M) had either bred the preceding season or carried a pouch young (PY) (age in days in parentheses). Age of PY was calculated from head length (TyndaleBiscoe, 1955). RPYn indicates that the sucking young was removed $\mathrm{n}$ days before PMSG treatment.

† Ovaries with no response $(\mathrm{N})$ had a smooth surface or follicles $<2.0 \mathrm{~mm}$ in diameter. Poor response ovaries $(\mathrm{Y} / \mathrm{N})$ had several medium-sized follicles, $2-3.0 \mathrm{~mm}$ diameter. Responding animals $(\mathrm{Y})$ had several large/very large follicles (diameter $>3.0 \mathrm{~mm}$ ) projecting from the ovarian surface ('bunch of grapes' appearance). The number of large follicles on the left ovary is indicated in parentheses.

$\ddagger$ In either ovary.

\$Maximum degree of meiotic maturation achieved by follicular oocytes: GV, germinal vesicle with nucleolus; PRO, condensing chromosomes indicating resumption of prophase; MET, Metaphase I or II; PBI, first polar body; ZP, zona pellucida losing granulosa cells from its surface; DEG, degenerative changes present in oocytes.

- Natural single ovulations occurred spontaneously or after RPY. lov = recent single ovulation; $1 \mathrm{CL}=$ single corpus luteum; egg = unfertilized egg recovered from the tract.

days after PMSG; 2 (Nos $34 \& 45$ ) had recent natural ovulations (i.e. were in the preovulatory phase when treated); and 1 animal (No. 40) failed to respond to PMSG.

As in the earlier study there was little, or no, evidence of ovarian stimulation in animals that were preovulatory at the time of gonadotrophin treatment (Nos $34 \& 45$ ). Otherwise the reproductive status of the female did not appear to limit the superovulatory response. Immature, cycling, pregnant (No. 31) and lactating females all responded to a similar extent. Ovulated oocytes were recovered 1, 1.5 or 2 days after GnRH treatment. Oocytes in apparently freshly ovulated condition with a metaphase II spindle and first polar body were recovered from the oviduct, or shortly after arriving in the uterus, from 6 animals (Fig. 3). In 2 animals (Nos 31 \& 35) examined 2 days after GnRH the oocytes had begun to fragment and unequivocal chromosomal detail was not seen. The thickness of mucoid deposited on superovulated oocytes and their rate of tubal transport was similar to that seen in monovulatory cycles. 

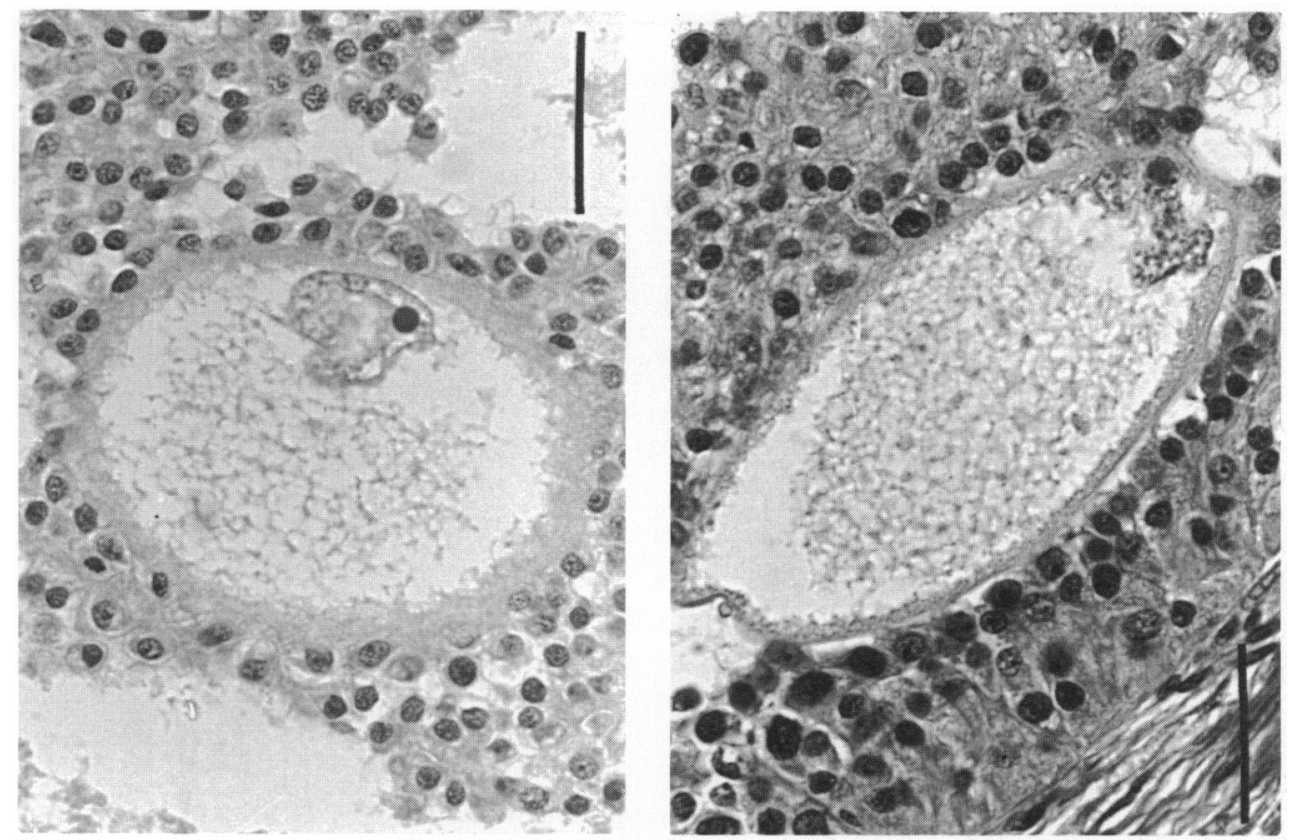

Fig. 1. Degenerate follicular oocytes in histological sections of the ovary of Possum 19. Both oocytes show marked disruption of the germinal vesicle envelope and displacement of the nucleolus. The zona pellucida at right has collapsed and is fragmenting. Bar $=50 \mu \mathrm{m}$.

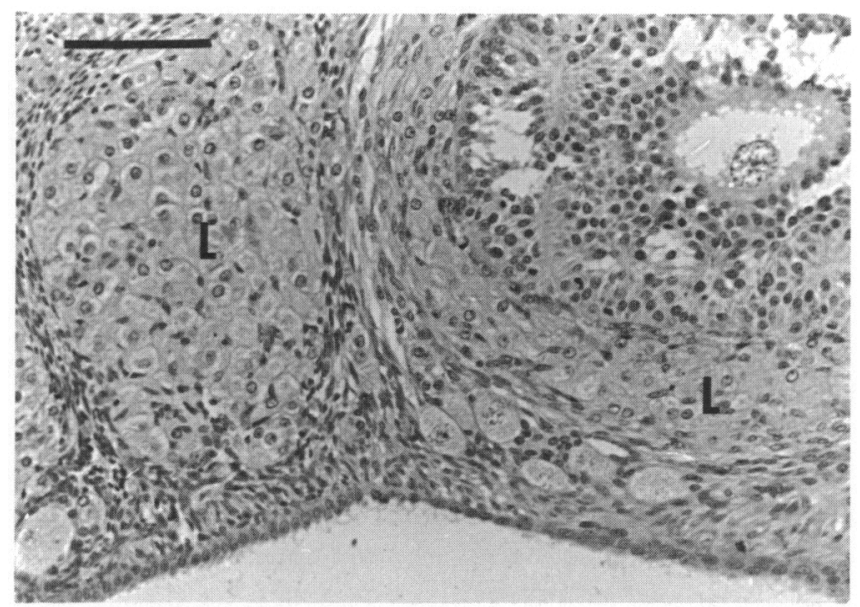

Fig. 2. A part of a Graafian follicle is seen to the right and nodules of luteinized tissue (L) to the left in this histological section of the ovary of Possum 19. The periphery of the follicle is also luteinized (L) and a trapped degenerating GV oocyte is present. Bar $=150 \mu \mathrm{m}$. 
Table 2. The response of the brush-tailed possum ovary to PMSG followed by GnRH

\begin{tabular}{|c|c|c|c|c|c|c|c|c|c|c|}
\hline \multirow{3}{*}{$\begin{array}{l}\text { PMSG } \\
\text { Dose on } \\
\text { Day 0 } \\
\text { (i.u.) }\end{array}$} & \multicolumn{2}{|c|}{ GNRH } & \multirow[b]{3}{*}{ Animal } & \multicolumn{7}{|c|}{ Response } \\
\hline & \multirow{2}{*}{$\begin{array}{c}\text { Dose } \\
(\mu \mathrm{g})\end{array}$} & \multirow[b]{2}{*}{ Day } & & \multirow{2}{*}{$\begin{array}{c}\text { Day } \\
\text { killed }\end{array}$} & \multirow[b]{2}{*}{$\mathrm{Y} / \mathrm{N}$} & \multirow{2}{*}{$\begin{array}{l}\text { Maximum } \\
\text { follicular } \\
\text { diam. }(\mathrm{mm})\end{array}$} & \multirow{2}{*}{$\begin{array}{l}\text { Oocyte } \\
\text { state }\end{array}$} & \multicolumn{2}{|c|}{$\begin{array}{l}\text { Ovula- } \\
\text { tions* }\end{array}$} & \multirow{2}{*}{$\begin{array}{c}\text { Natural } \\
\text { ovula- } \\
\text { tions }\end{array}$} \\
\hline & & & & & & & & $\mathrm{L}$ & $\mathbf{R}$ & \\
\hline 50 & 100 & 4 & $22 \mathrm{IM}$ & 6 & $\mathrm{Y} / \mathrm{N}(19)$ & $2 \cdot 1$ & GV/ZP & 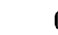 & & \\
\hline 50 & 100 & 4 & $21 \mathrm{M}$ & 6 & $\mathrm{~N}$ & - & - & ( & & $1 \mathrm{CL}$ \\
\hline 50 & 100 & 4 & $20 \mathrm{PY}(44)$ & 6 & $Y(25)$ & $4 \cdot 4$ & DEG/ZP & ( & & \\
\hline 50 & 175 & 4 & $23 \mathrm{aIM}$ & 6 & $\mathrm{Y} / \mathrm{N}(6)$ & $2 \cdot 2$ & $\mathrm{GV} / \mathrm{ZP}$ & ( & & $1 \mathrm{CL}$ \\
\hline 50 & $3 \times 50$ & 4 & $23 \mathrm{bIM}$ & 6 & $Y(6)$ & $4 \cdot 2$ & $\mathrm{DEG} / \mathrm{ZP}$ & ( & & \\
\hline 50 & $3 \times 50$ & 4 & $24 \mathrm{M}$ & 7 & $Y(9)$ & $5 \cdot 0$ & $\mathrm{MET} / \mathrm{DEG}$ & ( & & \\
\hline 10 & $3 \times 50$ & 3 & $25 \mathrm{M}$ & 4 & $Y(9)$ & $4 \cdot 4$ & $\mathrm{MET} / \mathrm{PBI}$ & ( & & \\
\hline 10 & $3 \times 50$ & 3 & $34 \mathrm{M}$ & 5 & $Y(-)$ & $3 \cdot 5$ & - & ( & & $1 \mathrm{CL} / \mathrm{egg}$ \\
\hline 10 & $3 \times 50$ & 3 & $39 \mathrm{PY}(>60)$ & 4 & $Y(9)$ & $3 \cdot 5$ & GV & ( & & \\
\hline 10 & $3 \times 50$ & 3 & $40 \mathrm{PY}(>60)$ & 7 & $\mathrm{~N}$ & - & - & ( & & \\
\hline 10 & $3 \times 50$ & 3 & $45 \mathrm{PY}(>60)$ & 4 & $\mathrm{~N}$ & - & - & ( & & $1 \mathrm{CL} \dagger$ \\
\hline 10 & $3 \times 50$ & 3 & $41 \mathrm{IM}$ & 4 & $\mathrm{Y}$ & - & - & 7 & 2 & \\
\hline 10 & $3 \times 50$ & 3 & 46 IM & 4 & $\mathrm{Y}$ & - & $\ldots$ & 6 & 9 & \\
\hline 10 & $3 \times 50$ & 3 & $26 \mathrm{M}$ & 5 & $\mathrm{Y}$ & $4 \cdot 2$ & - & 2 & 6 & \\
\hline 10 & $3 \times 50$ & 3 & $30 \mathrm{M}$ & $4 \cdot 5$ & Y & $3 \cdot 2$ & - & 5 & 8 & egg \\
\hline 10 & $3 \times 50$ & 3 & $31 \mathrm{M}$ & 5 & $\mathrm{Y}$ & - & - & 12 & 5 & embryot \\
\hline 10 & $3 \times 50$ & 3 & 35 PY (5) & 5 & $\mathrm{Y}$ & - & - & 0 & 10 & ICL \\
\hline 10 & $3 \times 50$ & 3 & 37 PY(21) & 5 & $\mathrm{Y}$ & - & - & 11 & 13 & \\
\hline 10 & $3 \times 50$ & 3 & 38 PY (63) & 5 & $\mathrm{Y}$ & - & - & 5 & 4 & \\
\hline
\end{tabular}

Abbreviations as in Table 1.

*Number of gonadotrophin-induced ovulations on left $(L)$ and right $(R)$ side of reproductive system. $0=$ no induced ovulations.

$\nmid$ Pouch young removed before treatment.

$\ddagger$ Embryo = trilaminar blastocyst.

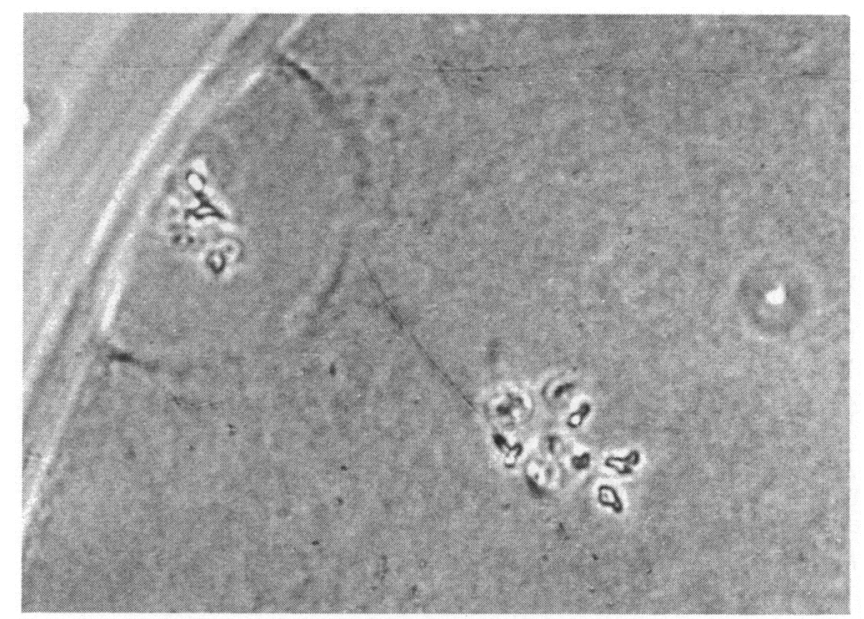

Fig. 3. A fixed and stained whole mount of an ovulated oocyte collected from Possum 46. The first polar body is to the left and the metaphase II chromosomes to the right. 


\section{Discussion}

Brush-tailed possums superovulated in a predictable and reliable manner when treated with 10 i.u. PMSG followed 3 days later by 3 doses of $50 \mu \mathrm{g} \mathrm{GnRH} \mathrm{(90} \mathrm{min} \mathrm{apart).} \mathrm{This} \mathrm{regimen} \mathrm{appears} \mathrm{to} \mathrm{be}$ applicable to immature and mature females in all reproductive states except the immediately preovulatory period, confirming the pattern of responsiveness found by Harding (1969). Degenerative changes in follicular oocytes and luteinization of the ovary occurred with doses of PMSG greater than 10 i.u. and when GnRH treatment was given on Day 4 rather than Day 3. Similar signs of gonadotrophin over-stimulation are commonly encountered in eutherian mammals, particularly cattle and sheep.

Multiple GnRH injections were tested, after single doses failed to yield ovulation in the possum, on the basis of data for the tammar wallaby. This relatively closely related monovulatory species has a $12-\mathrm{h}$ natural $\mathrm{LH}$ surge but a single treatment with GnRH induces a surge of only $1.5 \mathrm{~h}$ duration (Evans et al., 1980; Sutherland et al., 1980). The precise time of ovulation remains unclear although it had recently occurred in 2 out of 3 possums examined $24 \mathrm{~h}$ after GnRH and essentially mucoid-free oocytes were recovered from the tracts. In the tammar wallaby the LH surge reaches a peak $25 \mathrm{~min}$ after GnRH (Evans et al., 1980) and ovulation occurs as early as $20 \mathrm{~h}$ after the LH surge (Sutherland et al., 1980; Harder et al., 1985). The timing of the possum's ovulatory response to GnRH (around $24 \mathrm{~h}$ ) therefore appears similar to that of the tammar. Precise timing of oocyte maturation and ovulation after GnRH are major aims of work in progress.

In contrast with the earlier possum work we failed to achieve superovulation with PMSG alone. Harding (1969) found multiple "ovulation points" in 14 animals across all her treatment regimens but oocytes tended to be retained in the ruptured follicles and only 3 animals superovulated. Harding (1969) used multiple PMSG injections, generally in rising doses for 3, 8 or 9 days (12.5 or $25 \mathrm{i} . \mathrm{u}$. rising to 100 or $200 \mathrm{i} . \mathrm{u}$./day). Of the 3 animals successfully superovulated 2 also received 100 i.u. hCG on the afternoon of Day 3 of the PMSG regimen, an ovulation induction strategy similar to that used here. As in the present study, Harding (1969) found that excessive PMSG treatment led to abnormal changes in the ovary including vascularization of follicles, failure to ovulate and luteinization. Similar abnormal changes were reported after exogenous gonadotrophin treatment of the American opossum (Morgan, 1946; Guraya, 1968).

We chose a single PMSG dose strategy to minimize such over-stimulation effects and to produce a simpler more practical method. In a preliminary experiment, using a mouse ovarian weight bioassay, PMSG was found to have a circulating half-life of 1-2 days in the brush-tailed possum, similar to that for rabbits and sheep (Lamond, 1960; McIntosh et al., 1975). After an adequate single dose stimulatory levels of PMSG could then be expected to persist in the animal for several days. Presumably the ovulations observed by Harding (1969) after prolonged PMSG treatment alone reflect follicular oestradiol-induced LH surges due to the number of large follicles recruited. In the ovariectomized tammar wallaby low concentrations of exogenous oestradiol depress pituitary gonadotrophin production but at high levels an LH surge occurs of a size and duration similar to those in natural cycles (Horn et al., 1985). Treatment with oestradiol may prove an alternative method of ovulation induction to GnRH but its use after PMSG has yet to be examined.

The present study does not provide evidence of the fertility of superovulated possum eggs or of the occurrence of oestrous behaviour and mating, but our primary aim was achieved. A simple method has been devised which reliably leads to superovulation of mature oocytes and their subsequent tubal transport and the mucoid coat deposited are of normal character.

We thank Ms Lisa Ford for her skilled technical assistance and the Australian Research Grants Scheme and the Senate Research Committee of the University of Newcastle for financial assistance. 


\section{References}

Bedford, J.M. (1971) Techniques and criteria used in the study of fertilisation. In Methods in Mammalian Embryology, ch. 3, pp. 37-63. Ed. J. C. Daniel. Freeman, San Francisco.

Evans, S.M., Tyndale-Biscoe, C.H. \& Sutherland, R.L. (1980) Control of gonadotrophin secretion in the female tammar wallaby (Macropus eugenii). $J$. Endocr. 86, 13-23.

Guraya, S.S. (1968) Histochemical observations on the granulosa and theca interna during follicular development and corpus luteum formation and regression in the American opossum. J. Endocr. 40, 237-241.

Harder, J.D., Hinds, L.A., Horn, C.A. \& Tyndale-Biscoe, C.H. (1985) Effects of removal in late pregnancy of the corpus luteum, Graafian follicle or ovaries on plasma progesterone, oestradiol, LH, parturition and post-partum oestrus in the tammar wallaby, Macropus eugenii. J. Reprod. Fert. 75, 449-459.

Harding, H.R. (1969) Studies on the periovulatory changes in the ovary, uterus and vagina of the marsupial Trichosurus vulpecula Kerr, and the effect of pregnant mare serum (PMS) and human chorionic gonadotrophin (HCG) in inducing ovulation. Honours thesis, University of NSW.

Horn, C.A., Fletcher, T.P. \& Carpenter, S. (1985) Effects of oestradiol-17ß on peripheral plasma concentrations of LH and FSH in ovariectomized tammar's (Macropus eugenii). J. Reprod. Fert. 73, 585-592.

Lamond, D.R. (1960) Gonadotrophins in rabbit serum after intravenous injection. J. Physiol., Lond. 151, 403-409.

McIntosh, J.E., Moor, R.M. \& Allen, W.R. (1975) Pregnant mare serum gonadotrophin: rate of clearance from the circulation in sheep. J. Reprod. Fert. 44, 95- 100 .

Morgan, C.F. (1946) Sexual rhythms in the reproductive tract of the adult female opossum and effects of hormonal treatments. Am. J. Anat. 78, 411-463.
Nelson, O.E. \& Maxwell, N. (1941) Induced oestrus and mating in the opossum, Didelphis virginiana. Anat. Rec. 81, 105, Abstr.

Nelson, O.E. \& White, E.T. (1941) A method of inducing ovulation in the anoestrous opossum, Didelphis virginiana. Anat. Rec. 81, 529-535.

Pilton, P.E. \& Sharman, G.B. (1962) Reproduction in the marsupial, Trichosurus vulpecula. J. Endocr. 25, 119-136.

Rodger, J.C. \& Bedford, J.M. (1982) Induction of oestrus, recovery of gametes, and the timing of fertilization events in the opossum, Didelphis virginiana. $J$. Reprod. Fert. 64, 159-169.

Rodger, J.C., Fletcher, T.P. \& Tyndale-Biscoe, C.H. (1985) Active anti-paternal immunization does not affect the success of marsupial pregnancy. J. Reprod. Immunol. 8, 249-256.

Smith, M.J. \& Godfrey, G.K. (1970) Ovulation induced by gonadotrophins in the marsupial Sminthopsis crassicaudata (Gould). J. Reprod. Fert. 22, 41-47.

Sutherland, R.L., Evans, S.M. \& Tyndale-Biscoe, C.H. (1980) Macropodid marsupial luteinizing hormone: Validation of assay procedures and changes in concentrations in plasma during the oestrous cycle in the female tammar wallaby (Macropus eugenii). $J$. Endocr. 86, 1-12.

Tyndale-Biscoe, C.H. (1955) Observations on the reproduction and ecology of the brush tailed possum, Trichosurus vulpecula (Kerr) (Marsupialia) in New Zealand. Aust. J. Zool. 3, 162-184.

Tyndale-Biscoe, C.H. \& Renfree, M.B. (1987) $R e$ productive Physiology of Marsupials, Cambridge University Press, Cambridge.

Tyndale-Biscoe, C.H. \& Hinds, L.A. (1984) Seasonal patterns of circulating progesterone and prolactin and the response to bromocriptine in the female tammar, Macropus eugenii. Gen. comp. Endocr. 53, 58-68.

Received 30 December 1987 